\title{
Prevalence of hypomagnesemia in neonatal seizures in a tertiary care hospital in South India
}

\author{
Suganthi $V^{1}$, Vikneshwari $K^{2}$, Thivya $G^{3}$ \\ ${ }^{1}$ Dr. Suganthi.V, Professor \& HOD, ${ }^{2}$ Dr. Vikneshwari. K, Junior Resident, ${ }^{3}$ Dr.Thivya.G, Junior Resident, all authors are \\ affiliated with Department of Pediatrics, Coimbatore Medical College Hospital, Trichy Road, Coimbatore-641018.Tamil \\ Nadu, India.
}

Address for Correspondence: Dr. Suganthi. V, Professor \& HOD, Department of Pediatrics, Coimbatore Medical College Hospital, Coimbatore. E-mail id suganthi_17365@yahoo.com

\begin{abstract}
Introduction: Metabolic causes of neonatal seizures with good prognosis are hypoglycemia, hypocalcemia, hypomagnesemia. Some of hypocalcmic seizures are accompanied by hypomagnesemia, but magnesium levels are rarely investigated in resource restricted hospitals. Materials and Methods: A group of 150 neonates with seizures were studied. Analysis of serum Calcium, Magnesium and Sodium were done on the samples using conventional methods. Prevalence of hypomagnesemia, hypocalcemia and their association was estimated. Results: Metabolic abnormalities were present in $89(59.3 \%)$ out of 150 cases. Of these, hypoglycemia and hypocalcemia were the most common with 39 (43.8\%) and 28 (35.4\%) cases respectively. The prevalence of hypomagnesemia was 5.3\%. 87\% of hypomagnesemia cases were associated with hypocalcemia implying the interrelation in pathophysiology. Among neonates with hypocalcemia, 20\% had hypomagnesemia. Hence, there is a need to estimate magnesium levels in neonatal seizures because treatment is definitive with magnesium salts. Conclusion: Hypomagnesemia was a significant cause of neonatal seizures. Most of the neonates with hypomagnesemia had an associated hypocalcemia. It is necessary to estimate levels of magnesium in addition to calcium in all neonates with seizures.
\end{abstract}

Keywords: Hypocalcemia, Hypomagnesemia, Metabolic, Neonatal, Seizures

\section{Introduction}

The most prominent neurologic dysfunction in the neonatal period is the occurrence of seizures. Symptomatic neonatal seizures may result from a wide range of possible etiologies [1]. The etiologies are categorized as hypoxic-ischemic encephalopathy, structural brain injuries, metabolic disturbances, central nervous system or systemic infections.Biochemical disturbances occur frequently in neonatal seizures either as a primary cause or as an associated abnormality. Potentially treatable metabolic etiologies include hypoglycemia, hypocalcemia and hypo-magnesemia.

These metabolic causes when treated appropriately are rarely associated with significant long term consequences [2]. Early hypocalcemia occurs in infants with hypomagnesemia.

Manuscript received: $29^{\text {th }}$ November 2016

Reviewed: $6^{\text {th }}$ December 2016

Author Corrected: $14^{\text {th }}$ December 2016

Accepted for Publication: $20^{\text {th }}$ December 2016
Hypomagnesemia causes resistance to parathormone secretion, resulting in hypocalcemia [3].

When both are associated, correction of hypocalcemia requires correction of hypomagnesemia [4].

Only few studies are available in Indian literature about the prevalence of hypomagnesemia in neonatal seizures and its association with hypocalcemia. Hence, this study was undertaken.

\section{Materials and Methods}

The present study was an observational study which included 150 neonates presenting with seizures, admitted to Neonatal Intensive Care Unit (NICU) of Coimbatore Medical College Hospital, Coimbatore during the period of one year from July 2014 to June 2015.

Inclusion criteria

1. Neonatal seizures occurring in the first 4 weeks of life. 
2. Neonates with seizures who were delivered at our hospital as well as outborn babies are included in the study.

3. Neonates presenting with at least one of the following clinical type of seizures were included.

- Subtle seizures

- Generalised tonic seizures

- Multifocal clonic seizures

- Focal seizures

- Myoclonic seizures

\section{Exclusion criteria}

1. Jitteriness in neonates.

2. Tetanic spasms in neonates.

3. Outborn neonates treated with anticonvulsants.

4. Infant of diabetic mother.

5.Newborn with congenital anomalies like hydrocephalus, Arnold Chiari malformation, Dandy Walker malformation.

Following investigations were done for neonatal seizures in all cases.

-Serum Calcium, Magnesium, Sodium.

-Hypocalcemia was defined when total serum calcium $<7.0 \mathrm{mg} / \mathrm{dl}$.
-Hypomagnesemia when serum $\mathrm{Mg}<1.5 \mathrm{mg} / \mathrm{dl}$

-Hyponatremia when $\mathrm{S} . \mathrm{Na}<135 \mathrm{meq} / \mathrm{L}$ and

-Serum Calcium estimation by O-Cresolphthalein Complexone (OCPC) method.

-Serum Sodium estimation by I.S.E Method (Ion Selective electrode)

-Serum Magnesium by Arsenazo dye binding method

Statistical Analysis- Statistical analysis was performed using the Statistical software package [SPPS version 16.0 for windows] (2) and consisted in computing the frequency count and percentages for qualitative variables, the mean and standard deviation for quantitative variables. The comparison of the percentages and the means were performed using the Chi-square test and the unpaired Student t-test.P -value $<0.05$ was considered significant.

Required sample size was calculated as 150 by power calculation formula

$$
\frac{\mathrm{n}=\mathrm{t}^{2} \times \mathrm{p}(1-\mathrm{p})}{\mathrm{m}^{2}}
$$

Where

$\mathrm{n}=$ required sample size

$\mathrm{t}=$ confidence level of $95 \%$

$\mathrm{p}=$ expected frequency of the factor under study

$\mathrm{m}=$ margin of error of $5 \%$

\section{Results}

Among the 150 study group hypoxic ischemic encephalopathy (HIE) was the most common cause of seizures (Table 1). It accounted for $39.3 \%$ followed by sepsis $32.7 \%$.Metabolic causes were $22 \%$, intracranial bleed was $4.7 \%$ and Inborn Errors of Metabolism (IEM) occupied the least common etiology (1.3\%).

Table-1: Causes of seizures in study group.

\begin{tabular}{|c|c|c|c|c|c|}
\hline & Sepsis & HIE & Hemorrhage & IEM & Metabolic \\
& $\mathbf{n}$ & $\mathbf{n}$ & $\mathbf{n}$ & $\mathbf{n}$ & $\mathbf{n}$ \\
\hline Isolated & 19 & 37 & 3 & 2 & - \\
\hline Combined with metabolic & 30 & 22 & 4 & - & 33 \\
\hline Total & 49 & 59 & 7 & 2 & $\mathbf{2 2 \%}$ \\
\hline
\end{tabular}

$\mathrm{n}=$ frequency of the cause of seizure 
Table-2: Distribution of age and gender in the study group.

\begin{tabular}{|c|c|c|c|c|}
\hline Age & Male & Female & Total & \% \\
\hline$<5$ DAYS & 68 & 51 & 119 & 79 \\
\hline $5-10$ DAYS & 10 & 04 & 14 & 09 \\
\hline $11-15$ DAYS & 08 & 06 & 03 & 02 \\
\hline$>15$ DAYS & 03 & 00 & $\mathbf{1 5 0}$ & \\
\hline Total & $\mathbf{8 9}$ & $\mathbf{6 1}$ & 14 & \\
\hline
\end{tabular}

In the selected group, during the study period, there was slight male preponderance in the occurrence of seizures with males occupying 59\% and females $41 \%$ (Table 2). In the selected study group, most common age of seizure occurrence was in "less than 5 days", group which occupied $79 \%$ of the total implying that neonates were vulnerable to seizures in their early neonatal period (Table 2). In the study group of 150 , term babies occupied $78 \%$ and preterm babies were $22 \%$ (Table 3 ).

Table- 3: Distribution of gestational age among the study group.

\begin{tabular}{|c|c|c|}
\hline Gestational age & $\mathbf{n}$ & $\mathbf{( \% )}$ \\
\hline Preterm & 33 & 22 \\
\hline Term & 117 & 78 \\
\hline Total & $\mathbf{1 5 0}$ & $\mathbf{1 0 0}$ \\
\hline
\end{tabular}

$\mathrm{n}=$ frequency of neonates

Table-4: Distribution of metabolic abnormality among the study group.

\begin{tabular}{|c|c|c|c|c|c|c|}
\hline & $\mathbf{n}$ & $\mathbf{\%}$ & Isolated & $\begin{array}{c}\text { Combined } \\
\text { with sepsis }\end{array}$ & $\begin{array}{c}\text { Combined } \\
\text { with HIE }\end{array}$ & $\begin{array}{c}\text { Combined with } \\
\text { Hemorrhage }\end{array}$ \\
\hline Hypoglycemia & 39 & 43.8 & 16 & 17 & 3 & 3 \\
\hline Hypocalcemia & 28 & 31.5 & 9 & 7 & 11 & 1 \\
\hline Hyponatremia & 6 & 6.7 & 0 & 3 & 3 & 0 \\
\hline $\begin{array}{c}\text { Hypogycemia } \\
\text { +hypocalcemia }\end{array}$ & 8 & 9 & 2 & 2 & 4 & 0 \\
\hline $\begin{array}{c}\text { Hypocalcemia } \\
\text { +hypomagnesemia }\end{array}$ & 7 & 7.9 & 6 & 1 & 0 & 0 \\
\hline Hypomagnesemia & 1 & 1.1 & 0 & 0 & 1 & $\mathbf{2 2}$ \\
\hline & $\mathbf{8 9}$ & $\mathbf{1 0 0}$ & $\mathbf{3 3}$ & $\mathbf{3 0}$ & & $\mathbf{4}$ \\
\hline
\end{tabular}

$\mathrm{n}=$ frequency of the metabolic abnormality

In the study group, metabolic abnormalities were present in 89 cases. Among metabolic abnormalities, hypoglycaemia and hypocalcemia were $43.8 \%$ and $31.5 \%$ respectively, followed by hypoglycaemia-hypocalcemia combination $9 \%$, hypocalcemia hypomagnesemia combination $7.9 \%$, hyponatremia $6.7 \%$ and hypomagnesemia $1.1 \%$ (Table 4 ).

Sepsis was most commonly associated with metabolic abnormalities (30 out of 49 cases). In this group, hypoglycemia was the most common metabolic abnormality (Table 4). Among the combined causes, HIE was second most commonly associated with other biochemical abnormalities. 22 cases out of 59 were associated with biochemical abnormalities and hypocalcemia was the most common metabolic abnormality associated with HIE.

The prevalence of hypomagnesemia was 5.3\% (8 cases). Of these, 7 cases were associated with hypocalcemia and 1 was isolated hypomagnesemia. Out of 7 cases of hypocalcemia- hypomagnesemia,-metabolic disturbance was the primary cause of seizures in 6 neonates and it was an associated abnormality (with sepsis) in one case. 


\section{Discussion}

In our study, 150 neonates were taken up according to the exclusion and inclusion criteria. Among the study group the most common cause of seizures was hypoxic ischemic encephalopathy (39.3\%) followed by sepsis $(32.6 \%)$, metabolic (22\%), intracranial bleed (4.7\%) and IEM (1.3\%). In a study on neonatal seizures by Moayedi AR et al [4], etiology of neonatal seizures was HIE (36.4\%) followed by infections (19.1\%), metabolic disorders $(7.3 \%)$, Intra cranial hemorrhage $(2.7 \%)$ and structural disorders $(1.8 \%)$.

This study has findings similar to our study. Based on different studies conducted, HIE was found to be the most common cause of neonatal seizures followed by infections, metabolic causes, hemorrhage and inborn errors of metabolism $[5,6]$.

Most common age group for the seizure occurrence in our study group was "less than 5days" age group in which seizure in first day was almost $40 \%$. In a study of neonatal seizures by Ronen Gabriel et al [7], onset of seizures on first day of life was $36 \%$; $64 \%$ had onset of seizures within first 48 hours and $83 \%$ within first week of life, this was similar to our study.

Onset of seizures within first 5 days constitutes the majority of cases, more so within first 48 hours of life. Neonatal seizures have no sex predilection. However, in our study, male to female ratio was $1.43: 1$, similar with the study of neonatal seizures by Hasan Tekgul et al [8], where male to female ratio was 1.5:1.

In the study group of 150 , term babies occupied $78 \%$ and preterm were $22 \%$. Similar observations were seen in study by Moayedi AR et al [4], where term AGA babies were $83.6 \%$, preterm were $12.7 \%$ and post term were $3.6 \%$. In a study by Abdur Rehman Malik [9], term babies were $69.8 \%$ and $30.2 \%$ preterm.

In our study, metabolic abnormalities were present in $89(59.3 \%)$ out of 150 cases; of which isolated cases were $33(37 \%)$ and those combined with HIE, sepsis, hemorrhage were 56 cases $(63 \%)$. Of the 89 cases, the commonest metabolic abnormality was hypoglycaemia $(43.8 \%)$, followed by hypocalcemia $(31.5 \%)$. Primary metabolic abnormalities were found in $17.5 \%$ cases in the study by Abdur Rheman Malik [9]. Ashok Kumar and Veenu Gupta [10], carried out a study on 35 neonates to determine the frequency of biochemical abnormalities in neonatal seizures. Two thirds $(66 \%)$ of neonates with seizures had biochemical abnormalities. Isolated metabolic abnormalities were present in $25 \%$. In a study by Sood A [11], in 59 neonates with seizures, primary metabolic abnormalities occurred in $10(16.94 \%)$ cases. In the current study, the prevalence of hypomagnesemia among 150 neonates with seizures was 5.3\% (8 cases). Of these, 7 were associated with hypocalcemia and 1 was isolated hypomagnesemia. Of the above 7 cases, 6 stood an isolated metabolic cause of seizure and 1 had sepsis. The 1 isolated hypomagnesemia was present in a neonate with HIE.

In our study, of the 35 neonates with hypocalcemia, $7(20 \%)$ had associated hypomagnesemia.V.K. Paul et al [12], did a study on seizures in 17 neonates and 8 young infants (1-3 months) to find the prevalence of hypomagnesemia. Hypocalcemia was the commonest cause of seizures in their study, occurring among 7(28\%) patients. $83.3 \%$ of them had associated hypomagnesemia. No case of isolated hypomagnesemia without hypocalcemia was seen.

Limitations-The limitations of the study was that the duration of study was only 12 months. There is still a need for research with large sample size and longer duration to find out the association between hypocalcemia and hypomagnesemia in a conclusive manner.

\section{Conclusion}

Hypomagnesemia constituted about $5.3 \%$ of the etiology of neonatal seizures. Most of the hypomagnesemia cases were associated with hypocalcemia, implying the interrelationship in pathophysiology. Hence, it is necessary to estimate the levels of magnesium in addition to calcium in all neonates with seizures.

Funding: Nil, Conflict of interest: None initiated, Perission from IRB: Yes

\section{References}

1. Volpe J J. Hypoxic-Ischemic encephalopathy; biochemical and physiological aspects. Neurology of the newborn $4^{\text {th }}$ ed. Philadelphia: NB Saunders; 2000. 217276.

2. Frances E. Jensen. Neonatal seizures: An update on Mechanisms and Management. Clin Perinatol. 2009 Dec; 36(4):881-900, vii. doi: 10.1016/j.clp.2009.08.001. 
3. Rubin LP. Disorders of calcium and phosphorous metabolism in Avery's Diseases of the newborn, $7^{\text {th }}$ ed, Taeush HW, Ballard RA (Eds), WB Saunders, Philadelphia 1998. p 1189.

4. Cockburn F, Brown JK, Belton NR, Forfar JO. Neonatal convulsions associated with primary disturbance of calcium, phosphorous and magnesium metabolism. Arch Dis child 1973;48:99-108.

5. Moayedi AR, Zakeri S.Neonatal seizure: Etiology and type. J Child Neurology 2007;2:1468.

6. Ajay Kumar, Ashish Gupta. Clinico -etiological and EEG profile of neonatal seizures. Indian J Pediatr. 2007 Jan; 74(1):33-7.

7. Brunquell Philip J. Prediction of outcome based on clinical seizurestypes in newborn infants. The Journal of Pediatrics 2002 Jun; 140 (6): 707 -12.

8. Ronen Gabriel M, Penny Sharon RN ,Andrews S Wayne. The epidemiology of clinical neonatal seizures in Newfordland : A population based study. The Journal of Pediatrics 1999 Jan; 134 (1):71-5.
9. Hasan Tekgul, Kimberlee Gauvreau. The current etiologic profile and neurodevelopmental outcome of seizures in term newborn infants. Pediatrics Pediatrics April 2006, volume 117 / issue 4.

10. Abdur Rehman Malik, Ahmed Irbal Quddusi Naila. Neonatal seizures, experience at Children Hospital and Institute of Health, Multan. Pak J Med Sci 2013 Sep Oct; 29(5):1128-1131.

11. Ashok kumar, Veenu Gupta, J. S. Kacchawaha, P.N. Singla. Biochemical abnormalities in neonatal seizures. Indian Pediatrics 1995; 32: 424428.

12. Aravind Sood ,Neelam Grover .Biochemical abnormalities in neonatal seizures. Indian Journal of Pediatrics 2003; 70(3):221-4.

13. Paul VK, Vaswani M, Singh M, Sekhar C, Deorari AK. Seizures in neonates and young infants due to hypomagnesemia. Indian J Pediatr. 1997 Sep-Oct; 64(5):725-7.

\section{How to cite this article?}

Suganthi V, Vikneshwari K, Thivya G. Prevalence of hypomagnesemia in neonatal seizures in a tertiary care hospital in South India. J PediatrRes.2017;4(01):63-67.doi:10.17511/ijpr.2017.i01.13 